\title{
Note
}

\section{Simplified protein hydrolysis with methanesulphonic acid at elevated temperature for the complete amino acid analysis of proteins}

\author{
SHYH-HORNG CHIOU* and KUNG-TSUNG WANG \\ Institute of Biochemical Sciences, National Taiwan University and Institute of Biological Chemistry, Academia \\ Sinica, P.O. Box 23-195, Taipei (Taiwan)
}

(First received March 25th, 1988; revised manuscript received May 23rd, 1988)

The importance of an accurate and convenient method of amino acid analysis for proteins and peptides is becoming increasingly obvious with the recent developments in biotechnology and protein engineering. The amino acid analyzer based on ion-exchange chromatography developed by Moore and Stein ${ }^{1,2}$ has remained the method of choice. The most commonly used conventional protocol of Hirs et al. ${ }^{3}$ utilizes $6 M$ hydrochloric acid and $110-120^{\circ} \mathrm{C} / 24 \mathrm{~h}$ for hydrolysis of most proteins. A time-course study of hydrolysis extended to $72 \mathrm{~h}$ is always needed to ensure a complete hydrolysis of peptide bonds next to some hydrophobic amino acids such as valine or isoleucine, in addition to correction for losses of some labile amino acids such as cystine, tyrosine, serine and threonine residues in the protein samples. The rate-determining step in a successful determination of amino acid compositions is thus dependent on the careful anaerobic preparation of protein hydrolysates and timeconsuming calibration and extrapolation of the data from different time courses of hydrolysis for these amino acids.

The determination of tryptophan by amino acid analysis is non-trivial. More than a decade ago, Simpson et al $^{4}$ introduced the non-volatile solvent, $4 \mathrm{M}$ methanesulphonic acid containing 3-(2-aminoethyl)indole in place of hydrochloric acid for complete amino acid analysis from a single protein hydrolysate. However, it has not hecome a standard method compared to the $6 M$ hydrochloric acid $/ 110^{\circ} \mathrm{C}$ protocol. Recently we have introduced rapid heating for protein hydrolysis using microwave irradiation ${ }^{5}$. During the refinement and application of this new technique, we have determined the temperature inside the microwave oven to be higher than $150^{\circ} \mathrm{C}$. This high temperature offers the advantage of shortening the hydrolysis time from $24 \mathrm{~h}$ to several minutes. With this finding in mind, we feel that it is important to study the effect of temperatures higher than the conventional $110^{\circ} \mathrm{C}$ for hydrolysis upon the accuracy of amino acid analyses for some standard proteins. Previous reports on the application of higher temperatures $\left(>150^{\circ} \mathrm{C}\right)$ in peptide and protein hydrolysis have emphasized the use of mixed-acid solvents such as hydrochloric acid-trifluoroacetic acid or-propionic acid ${ }^{6,7}$. In this report the use of a high temperature and shorter time has been applied to the amino acid analysis of proteins with a single non-volatile acid, $4 M$ methanesulphonic acid, which yields amino acid composition data including tryptophan and half-cystine. Some simplification and increase in speed relative to the conventional protocol of employing vacuum-sealed tubes in the $6 \mathrm{M}$ hydrochloric 
acid $/ 10^{\circ} \mathrm{C}$ hydrolysis can be achieved without loss of accuracy and performance in amino acid analyses of proteins and peptides.

\section{EXPERIMENTAL}

\section{Materials and equipment}

The Pyrex reusable hydrolysis tubes (4 mm I.D.) were ordered from the local glass shop according to the design shown in Fig. 1. Each tube can contain up to $5.0 \mathrm{ml}$ of solution without contact with the tip of the poly(tetrafluoroethylene) (PTFE) sealing cap. In practice, less than $1 \mathrm{ml}$ of hydrolysis solvent is added to the tube for the preparation of the protein or peptide hydrolysate. Each PTFE cap contains three sealing O-rings to ensure complete leak-free operation during high-temperature heating. Our design differs from the commercially available reusable hydrolysis tubes (Pierce Chemical Company, Rockford, IL, U.S.A.) in that it is based on the inert-gas flushing instead of the vacuum-sealing procedure for the removal of oxygen inside the tubes. Therefore one long arm of the Pyrex tube with a wide bore is used as the inlet of the flushing gas and the short arm opening with a small bore as the outlet of the inert gas (Fig. 1).

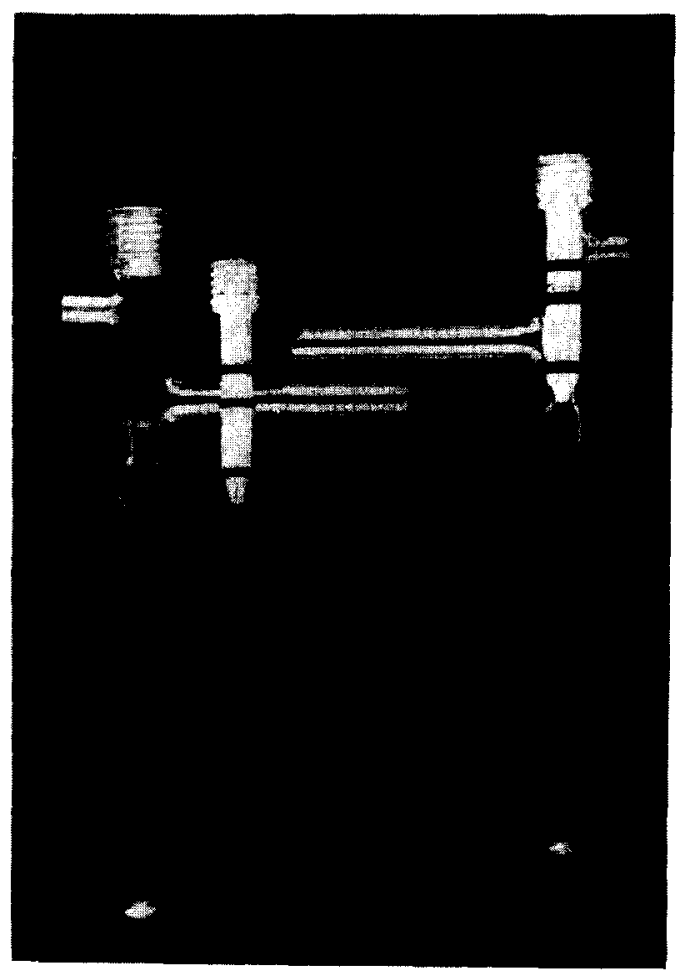

Fig. 1. The design of reusable Pyrex hydrolysis tubes used for the dry heating block. The PTFE cap contains three sealing $\mathrm{O}$-rings to ensure leak-free operation during high-temperature heating. The long-arm opening is the inlet used for flushing the tube with inert gas before heating. The short arm opening with a small bore is the outlet for the flushing gas. 
A Reacti-Therm dry block heating system (Pierce) was used as the heat source and was capable of reaching up to $165^{\circ} \mathrm{C}$ at maximum setting. The deviation of the temperature caused by the surrounding air current could be controlled to $0.5-1{ }^{\circ} \mathrm{C}$ by wrapping the whole block with aluminium foil.

$4 M$ Methanesulphonic acid containing $0.2 \%$ 3-(2-aminoethyl)indole and $3 M$ mercaptoethanesulphonic acid in 1-ml ampoules were obtained from Pierce. Native chicken egg white lysozyme and porcine heart lactate dehydrogenase were from Sigma (St. Louis, MO, U.S.A.). Cardiotoxin from the venom of Naja naja siamensis (Thailand cobra) was isolated, purified and sequenced in this laboratory ${ }^{8}$.

\section{Sample preparation and hydrolysis protocol}

Hydrolyses were carried out in the acid-cleaned and dry reusable hydrolysis tubes. Protein samples $(0.2-0.5 \mathrm{mg})$ were dissolved in $0.2-0.5 \mathrm{ml}$ methanesulphonic acid. The tubes with samples were each flushed with pure nitrogen gas for $1 \mathrm{~min}$ with gentle shaking. Then the outlet of the tube was closed with a finger and sealed by screwing down the PTFE cap. The tubes were put in the dry heating block at the pre-set temperature of $160^{\circ} \mathrm{C}$ for $45 \mathrm{~min}$ unless otherwise stated. At the end of heating, the acid-digested mixtures were pipetted into acid-cleaned vials and partially neutralized with $8 M$ sodium hydroxide (about 20-30 $\mu$ l of base per $200 \mu \mathrm{l}$ of methanesulphonic acid); the final mixture was checked with $\mathrm{pH}$-indicator paper to the colour range corresponding to $\mathrm{pH} 2$. The reaction mixture becomes cloudy when it is basic. The $\mathrm{pH}$-adjusted hydrolysate was diluted in the citrate buffer ( $\mathrm{pH} 2.2)$, filtered and applied to the LKB-4150 amino acid analyzer using a single-column system.

\section{Conditions for amino acid separation on an LKB-4150 analyzer}

The buffer formulations and the three buffers of successively higher $\mathrm{pH}$ were similar to those employed in the conventional protocol for the hydrochloric acid hydrolysate except that the sodium borate buffer of $\mathrm{pH} 10.0$ was used as the third buffer instead of the citrate buffer of $\mathrm{pH} 6.45$ (LKB-4150 elution program No. 10). Tryptophan was eluted between the peaks of histidine and lysine. The quantitation of tryptophan and other amino acids was precalibrated with a standard mixture of seventeen amino acids plus reagent-grade tryptophan. The instrument was equipped with an automated peak integrator. The correction factor for the colour constant of tryptophan was estimated as $72 \%$ of that for lysine based on a previous calibration of the 570-nm detector. The amino acid composition data including half-cystine and tryptophan were compared with the theoretical amino acid residue numbers reported for these proteins based on their sequences.

\section{RESULTS AND DISCUSSION}

Although conventional anaerobic hydrolysis of purified proteins with $6 M$ hydrochloric at $110^{\circ} \mathrm{C}$ for $24 \mathrm{~h}$ has been widely used for more than 30 years, a time-course study of the hydrolysis must be performed to obtain an accurate estimation of labile amino acids plus other stable amino acids such as isoleucine, valine and leucine ${ }^{9,10}$. Ideally, the less amount of sample preparation and hydrolysis time required, the lower is the risk of amino acid degradation during hydrolysis ${ }^{11}$. Therefore we have taken a systematic approach of a high temperature and 
TABLE I

\section{AMINO ACID ANALYSIS OF LYSOZYME UNDER DIFFERENT CONDITIONS}

Data are expressed as the number of residues per molecule of protein using alanine as the reference. Values represent the mean of triplicate determinations. Hydrolysis conditions: $4 M$ methanesulphonic acid, $110^{\circ} \mathrm{C} / 24 \mathrm{~h}$ or $160^{\circ} \mathrm{C}$ for different times using Pyrex reusable tubes flushed with nitrogen and dry heating block. The values in the parentheses are the theoretical residue numbers of various amino acids predicted from the protein sequence.

\begin{tabular}{lccccc}
\hline Amino acid & $110^{\circ} \mathrm{C} / 24 \mathrm{~h}$ & \multicolumn{5}{l}{$160^{\circ} \mathrm{C}$ for } \\
\cline { 3 - 5 } & & 15 & 30 & 45 & $90 \mathrm{~min}$ \\
\hline l/2Cys & $6.6(8)$ & 5.7 & 6.2 & 7.7 & 7.0 \\
Asx & $22.2(21)$ & 19.6 & 20.3 & 21.9 & 22.4 \\
Thr & $6.2(7)$ & 6.0 & 6.3 & 6.8 & 6.1 \\
Ser & $8.1(10)$ & 8.6 & 8.5 & 8.9 & 8.2 \\
Glx & $5.2(5)$ & 4.5 & 5.0 & 5.1 & 5.3 \\
Pro & $2.4(2)$ & 1.3 & 1.7 & 2.4 & 2.3 \\
Gly & $12.5(12)$ & 10.7 & 11.2 & 12.2 & 11.9 \\
Ala & 12 & 12 & 12 & 12 & 12 \\
Val & $5.3(6)$ & 4.2 & 4.7 & 5.8 & 6.1 \\
Met & $1.8(2)$ & 1.7 & 1.8 & 1.9 & 1.9 \\
Ile & $5.0(6)$ & 4.6 & 5.0 & 5.2 & 5.9 \\
Leu & $8.3(8)$ & 6.7 & 7.3 & 7.9 & 7.9 \\
Tyr & $3.5(3)$ & 2.6 & 2.7 & 3.5 & 2.7 \\
Phe & $2.8(3)$ & 1.8 & 2.3 & 3.3 & 3.0 \\
His & $0.8(1)$ & 0.4 & 0.6 & 0.6 & 0.8 \\
Lys & $5.3(6)$ & 4.2 & 4.8 & 6.1 & 5.8 \\
Arg & $1.6(11)$ & 9.5 & 9.9 & 11.5 & 10.7 \\
Trp & $5.8(6)$ & 5.4 & 5.6 & 5.6 & 5.4 \\
\hline
\end{tabular}

improvements in the pre-hydrolysis sample preparation to achieve accurate and comparable results to those of the conventional protocol ${ }^{12}$. Unexpectedly, we found that, by employing a higher temperature and a shorter time in the hydrolysis of proteins with methanesulphonic acid as originally proposed by Simpson et al. ${ }^{4}$, accurate results for all the amino acids, including tryptophan and half-cystine, were obtained from a single hydrolysate.

Fig. 1 shows the reusable hydrolysis tubes which are designed for the purpose of inert-gas flushing and high-temperature hydrolysis using a dry heating block. Previous experience has shown the applicability of this convenient alternative to that of the conventional one using disposable vacuum-sealed tubes and an oven at $110^{\circ} \mathrm{C}^{12}$. The reason for adopting $160^{\circ} \mathrm{C}$ and $45 \mathrm{~min}$ instead of $110^{\circ} \mathrm{C}$ and $24 \mathrm{~h}$ is that in general the hydrolysis rate doubles for every $10^{\circ} \mathrm{C}$ increase in temperature according to the theory of the temperature dependence of reaction rates ${ }^{13}$. For example, the time required for the heating at $160^{\circ} \mathrm{C}$ will be $24 \mathrm{~h} / 2^{5}=0.75 \mathrm{~h}$ to ensure a similar peptide-bond hydrolysis at $110^{\circ} \mathrm{C}$ and $24 \mathrm{~h}$.

In this study the recoveries of most amino acids at the higher temperature and shorter time were similar to those obtained from the conventional protocol (Table I), in accordance with the correlation of temperature and hydrolysis rate. Table I also shows that the minimum heating time for lysozyme hydrolysis using $4 M$ methanesulphonic acid at $160^{\circ} \mathrm{C}$ is more than $30 \mathrm{~min}$ since the hydrolyses for 15 and $30 \mathrm{~min}$ 
clearly indicated incomplete recoveries of several amino acids. In general the recoveries of the amino acids fall within a constant range of $97-102 \%$ at $160^{\circ} \mathrm{C}$ for $45 \mathrm{~min}$ using this non-volatile solvent, with the exception of hydrophobic amino acids such as valine and isoleucine. The lower yields of these two amino acids in the conventional $6 M$ hydrochloric acid/ 24 h procedure necessitate additional hydrolyses for longer times, which also holds true for the present protocol. Hydrolysis at $160^{\circ} \mathrm{C}$ for $90 \mathrm{~min}$ improves the yields for these two amino acids at the expense of good recoveries for cysteine and tryptophan. However the results from methanesulphonic acid hydrolysis are not inferior to those of the conventional protocol, and methanesulphonic acid offers the additional advantage of a reliable estimation of cysteine and tryptophan. Another striking feature of high temperature hydrolysis for a shorter time is the prevention of serine, threonine and tyrosine from destruction which occurs during prolonged hydrolysis (Table I).

In the original protocol for methanesulphonic acid hydrolysis proposed by Simpson et al.$^{4}$, proteins were hydrolyzed in vacuo at $115^{\circ} \mathrm{C}$ for 22,48 and $72 \mathrm{~h}$ similar to the conditions of conventional $6 M$ hydrochloric acid hydrolysis. In this report we show that the adoption of a higher temperature and proportionally less time gives data similar to those from the old protocol. In addition we found that cysteine could also be estimated without the chemical modification of sulphydryl groups by carboxymethylation ${ }^{4}$ or performic acid oxidation ${ }^{3}$. The method described here is also superior to that of Penke et al. ${ }^{14}$. who used $3 \mathrm{M}$ mercaptoethanesulphonic acid for the determination of tryptophan in proteins. Fig. 2 shows the elution patterns for lysozyme analyses with these two different solvents. About $90 \%$ of cysteine residues were recovered after hydrolysis at $160^{\circ} \mathrm{C}$ for $45 \mathrm{~min}$ with $4 M$ methanesulphonic acid, whereas these residues were completely destroyed under the same conditions of hydrolysis with $3 M$ mercaptoethanesulphonic acid. A recent report by $\mathrm{Ng}$ et al. ${ }^{15}$ on
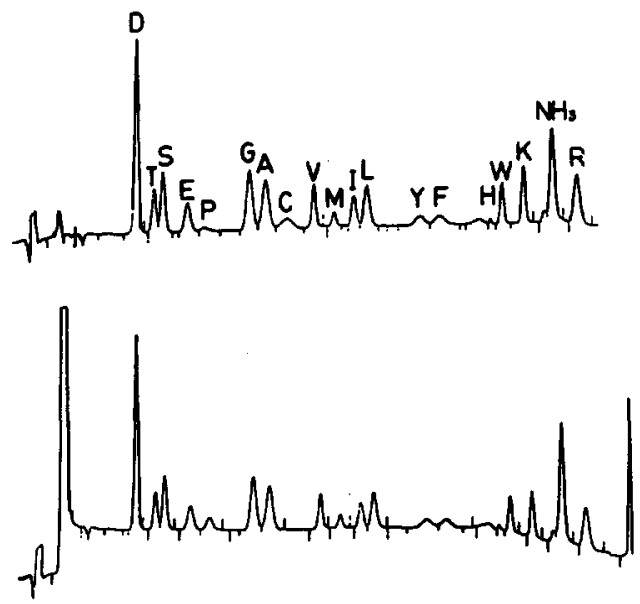

Fig. 2. Amino acid separation patterns of the lysozyme hydrolysates on an LKB-4150 analyzer. The buffer formulation and conditions are as described in Experimental. (Top) Amino acid analysis of lysozyme hydrolyzed with $4 M$ methanesulphonic acid. (Bottom) Amino acid analysis of lysozyme hydrolyzed with $3 \boldsymbol{M}$ mercaptoethanesulphonic acid. The peaks of the various amino acids eluted are denoted with one-letter symbols. Note the complete absence of the cystine peak from the lower figure. 
TABLE II

\section{AMINO ACID ANALYSIS OF LACTATE DEHYDROGENASE AND CARDIOTOXIN}

Data are expressed as the number of residues per molecule of protein based on the total residues of 333 and 60 for lactate dehydrogenase and cardiotoxin, respectively. Values represent the mean of triplicate determinations. Hydrolysis conditions: $160^{\circ} \mathrm{C}$ for 45 min using $4 M$ methanesulphonic acid. The values in the parentheses are the theoretical residue numbers of amino acids predicted from the protein sequences.

\begin{tabular}{lcl}
\hline Amino acid & Lactate dehydrogenase & Cardiotoxin \\
\hline 1/2Cys & $4.8(5)$ & $7.7(8)$ \\
Asx & $36.4(36)$ & $8.1(8)$ \\
Thr & $13.4(14)$ & $2.8(3)$ \\
Ser & $24.8(26)$ & $2.7(3)$ \\
Glx & $33.7(33)$ & $0.2(0)$ \\
Pro & $10.7(11)$ & $3.9(4)$ \\
Gly & $24.6(24)$ & $1.9(2)$ \\
Ala & $21.2(20)$ & $2.1(2)$ \\
Val & $39.1(39)$ & $3.9(4)$ \\
Met & $8.7(9)$ & $3.3(3)$ \\
Ile & $22.1(23)$ & $3.6(4)$ \\
Leu & $36.7(36)$ & $5.9(6)$ \\
Tyr & $6.2(7)$ & $2.0(2)$ \\
Phe & $4.9(5)$ & $1.0(1)$ \\
His & $6.8(7)$ & $0.3(0)$ \\
Lys & $24.6(24)$ & $8.1(8)$ \\
Arg & $8.1(8)$ & $1.9(2)$ \\
Trp & $6.1(6)$ & $0.1(0)$ \\
\hline
\end{tabular}

the use of hydrochloric acid hydrolysis of proteins in the presence of $0.4 \%$ 2-mercaptoethanol for the determination of tryptophan by reversed-phase highperformance liquid chromatography (HPLC) also encountered the problem of destruction of cysteine residues. The presence of sulphydryl reducing groups in the hydrolysis solvent probably also acts as a catalyst in the oxidation of cysteine and other labile amino acids during the process of high temperature hydrolysis.

In conclusion, high temperature hydrolysis with $4 M$ methanesulphonic acid has been successfully applied to the amino acid analysis of peptides and proteins. The salient feature of this protocol is that the complete amino acid content including the determination of cysteine and tryptophan is obtained with a single protein hydrolysate without previous chemical modification of the proteins. The hydrolysis time has been shortened to $45 \mathrm{~min}$ from $24 \mathrm{~h}$ without loss of accuracy and performance. The method should prove to be of great value in the analysis of other large and small proteins as shown by our analysis of porcine lactate dehydrogenase (140000 daltons) and snake venom toxin (7000 daltons) (Table II). With the recent advancement of instrumentation for amino acid analysis or HPLC there is a great advantage to shortening the pre-analysis hydrolysis process with the potential of on-line automation of the complete process of amino acid analysis starting from the preparation of protein hydrolysates. 


\section{ACKNOWLEDGEMENTS}

We are grateful for the generous support of Academia Sinica and the National Science Council, Taipei, Taiwan.

\section{REFERENCES}

1 S. Moore and W. H. Stein, J. Biol. Chem., 192 (1951) 663.

2 S. Moore and W. H. Stein, J. Biol. Chem., 211 (1954) 893.

3 C. H. W. Hirs, W. H. Stein and S. Moore, J. Biol. Chem., 211 (1954) 941.

4 R. J. Simpson, M. R. Neuberger and T.-Y. Liu, J. Biol. Chem., 251 (1976) 1936.

5 S.-T. Chen, S.-H. Chiou, Y.-H. Chu and K.-T. Wang, Int. J. Pept. Protein Res., 30 (1987) 572.

6 A. Tsugita and J.-J. Scheffler, Eur. J. Biochem., 124 (1982) 585.

7 F. C. Westall, J. Scotchler and A. B. Robinson, J. Org. Chem., 37 (1972) 3363.

8 S.-H. Chiou, W.-W. Lin and W. P. Chang, Int. J. Pept. Protein Res., (1988) submitted for publication.

9 S. Moore, D. H. Spackman and W. H. Stein, Anal. Chem., 30 (1958) 1185.

10 D. H. Spackman, W. H. Stein and S. Moore, Anal. Chem., 30 (1958) 1190.

11 P. E. Hare, Methods Enzymol., 47E (1977) 3.

12 S.-H. Chiou, J. Chromatogr., (1988) submitted for publication.

13 P. W. Atkins, in Physical Chemistry, Freeman, San Francisco, 1978, p. 864.

14 B. Penke, R. Ferenczi and K. Kovacs, Anal. Biochem., 60 (1974) 45.

15 L. T. Ng, A. Pascaud and M. Pascaud, Anal. Biochem., 167 (1987) 47. 